International Journal of Social Science And Human Research

ISSN(print): 2644-0679, ISSN(online): 2644-0695

Volume 05 Issue 02 February 2022

DOI: 10.47191/ijsshr/v5-i2-09, Impact factor-5.586

Page No: $440-446$

\title{
Emotional Intelligence as Correlate of Academic Performance among Junior Secondary School Students in Katsina Metropolis
}

\author{
S. Y. Tsagem ${ }^{1}$, Jamilu Bello ${ }^{2}$ \\ ${ }^{1}$ Department of Educational Foundations, Usmanu Danfodiyo University Sokoto P. M. B. 2346, Sokoto, Nigeria \\ ${ }^{2}$ Department of Education, Yusuf Bala College of Legal and General Studies, Daura - Katsina State, Nigeria
}

\begin{abstract}
The study examined emotional intelligence as correlate of academic performance among junior secondary school students in Katsina metropolis. A sample of 384 students was drawn from a population of (8757) junior secondary schools students in the metropolis. Two instruments were used in obtaining the data for the study; an adopted version of Emotional Intelligence Questionnaire (EIQ) designed by Kolo (2006) and JSS II results in English and Mathematics which was used to measure academic performance of students. Three hypotheses were tested and results obtained showed that emotional intelligence was related to academic performance for both males and females junior secondary school students in Katsina metropolis. Based on these findings therefore, it is recommended that effort should be made towards training in the development and sustenance of positive motivation. Conclusively, it is pertinent to emphasize on developing self-awareness among learners so as to produce learners who are emotionally stable, capable of controlling their moods, resilient to stress, rational in their thinking, flexible in their approach, confident in themselves, and with positive attitude towards themselves and their abilities.
\end{abstract}

\section{INTRODUCTION}

There is no disputing the fact that education is a fundamental tool for total development of the individual. The purpose of educational experience is learning, a process through which students develop skills and knowledge through a variety of experiences that are designed and monitored by teachers (Fafunwa, 1976). The out-come for the many students who pass through this system is to emerge with confidence as positive contributing members of their societies. A teacher, in a professional usage, is a person trained or recognized and employed to help learning in a classroom situation in order to achieve set educational goals. In ordinary usage however, the term is often used to refer to anybody who imparts information or knowledge or merely instructs another (Adeyinka, 2002). To Salawu (1993), teachers are the agents of socialization of their children; they shape the behavior of these children directly or indirectly. The implementation of any curriculum depends to a large extent on the availability of the right type of educational personnel and their willingness to impact the desired knowledge to a learner. The education for the good life has been one of the most persistent concerns of students' motivation throughout the ages (Fafunwa, 1976). Education is expected to affect behavior of educated people or the people being educated. Thus, education is equated at times with achievement, certification or accomplishment (Salawu, 2000). Of importance in attaining educational achievement is the impact of emotional intelligence of the learner.

Goleman (1995) sees emotional intelligence as the capacity for recognizing our own feelings and those of others, for motivating ourselves for managing emotion well in ourselves and in our relationship. Emotional intelligence (EI) is the area of cognitive ability involving traits and social skills that facilitate interpersonal behavior. Intelligence can be broadly defined as the capacity for goal-oriented adaptive behavior; emotional intelligence focuses on the aspects of intelligence that govern selfknowledge and social adaptation. Mayer and Salouey (1987) as cited in Goleman (1995) defined emotional intelligence as the ability to monitor one's and others' emotion to discriminate among and to use this information to guide one's thinking and action. To them, emotional intelligence comprises four broad and interrelated competences, perception, appraisal and expression of emotion to facilitate thinking, understanding, analyzing and implementing emotional knowledge and managing emotion.

Emotional intelligence is describe as the art of handling emotionally charged situation, the ability to stay focused under or which conflict, handle criticism, diffuse anger and manage other forms of confrontation that can make or break one in life, it requires emotional intelligence to make it to the top. A child's emotional state at school is said to influence his/her selective attention, recall, event interpretation, decision making, motivation and problem solving abilities (Mont, 2008). These in turn affect his academic performance. According to Akinboye (2002) emotional intelligence is associated with success at school, because social and emotional skills have been found to create higher educational performance. It was estimated that $80 \%$ of human success could be attributed to emotional intelligence while the remaining $20 \%$ belongs to intelligence quotient. 


\section{Emotional Intelligence as Correlate of Academic Performance among Junior Secondary School Students in Katsina Metropolis}

Akinboye (2003) described emotional intelligence as the ability to organize emotions driven perception, intuition and thought processes plus the ability to express such emotion-laden behaviors inter personally as well build trust, honesty, fairness, human dignity and integrity in life. Mcluskey (1997) explained emotional intelligence as the mental ability we are born with which give us our emotional sensitivity and our potentials for emotional learning management skills which can help us maximize our long term health, happiness and survival. All the definitions and explanations of emotional intelligence revealed an agreement as they all tend to point to the same direction, which is, being intelligence with emotions and using the message passed to resolve all life conflicts.

Academic performance refers to how well students can accomplish the classroom task given to them by their teachers; it is the extent at which they cope with their studies in relation to the stipulated aims and objectives of the school. Academic performance is usually reflected in learner's ability to be able to communicate the knowledge they have acquired within a given period of time verbally or most of the time, to put it down on paper and measured using test or any other valid instrument. It can also refer to the measure of students' academic output which can be determined by the grade they obtained at the end of a program. However, if student grades are high, such are called high achievers or low achievers.

The study was based upon the learning theories especially that of John B. Watson (1878-1959). Their conceptual frameworks describe how information is absorbed, processed, and retained during learning. Cognitive, emotional, and environmental influences, as well as prior experience, all play a part in how understanding, or a world view, is acquired or changed, and knowledge and skills retained.

In Nigeria today, as in many other African countries, the society is more complex than it was before. This has inevitably meant that more contemporary methods of solving problems need to be applied than the simple methods of the past. In Nigeria, especially, the fundamental objective of education is the ability of an individual to think and find new solution to his/her problems and society at large. Thus, the concern of emotional intelligence was succinctly forwarded and equally taken care of.

\section{STATEMENT OF THE PROBLEM}

Failure in examination poses the danger of populating the streets with drop-out, half-educated, maladjusted; unemployed that can only constitute social menace and a threat to the peace and stability of the society. Thus, it will compromise the country's aspiration to the future leadership of the African continent and it robs the country of taking its rightful position among the advanced nations of the world. Because, quite often students do not have the same perception of themselves (Lane, 1998), understanding the students' perception through teachers' motivation is important because specific students' outcomes are influenced by these perceptions. Furthermore, many teachers are not efficient in terms of selecting the methods that they should apply or use to a particular group to motivate students for them to maximally achieve in the learning process. Because literature related to the teaching-learning process has continuously pointed to the importance of motivation, its role could never be easily overemphasized.

Thus, the basic problem of this study therefore was to investigate the relationship between students' motivation and academic performance of junior secondary II Students in Katsina metropolis.

\section{RESEARCH QUESTIONS}

In order to carry out this research study, the following research questions were developed to guide the conduct of the study.

1. Is there any relationship between students' emotional intelligence and academic performance?

2. Is there any relationship between male students' emotional intelligence and their academic performance?

3. Is there any relationship between female students' emotional intelligence and their academic performance?

\section{RESEARCH OBJECTIVES}

The objectives set for this study were to find out:

1. If there is relationship between students' emotional intelligence and their academic performance.

2. If there is relationship between male students emotional intelligence and their academic performance.

3. If there is relationship between female students emotional intelligence and their academic performance

\section{Research Hypotheses}

In order to provide answers to the research questions stated, the following hypotheses were formulated.

H01 There is no significant relationship between students' emotional intelligence and academic performance.

$\mathbf{H O}_{2}$ There is no significant relationship between male students' emotional their intelligence and academic performance students.

H03 There is no significant relationship between females' students' emotional their intelligence and academic performance.

\section{RESEARCH DESIGN}




\section{Emotional Intelligence as Correlate of Academic Performance among Junior Secondary School Students in Katsina Metropolis}

The design for this study was descriptive design of the correlational type. Correlational research has been defined as a study aimed at establishing the relationship that exists between two or more variables for the purpose of making a prediction about the relationship. This research design was used because it enables the researcher not only to observe methodologically existing attributes in the population but also to see relationship between the variables.

In this study, the variables of interest under study are students' emotional intelligence and academic performance. Measure of students' emotional intelligence is the independent variable because it is antecedent to academic performance which is the dependent variable

\section{POPULATION OF THE STUDY}

The population of this study were Junior Secondary School II (JSSII) students in Katsina metropolis. In all, there are a total of thirtytwo (32) Junior Secondary Schools in the metropolis. The total number of the students' population was eight thousand seven hundred and fifty seven $(8,757)$. The schools were of three categories; mixed (boys and girls), males' (boys) only and female (girls) only.

\section{SAMPLES AND SAMPLING TECHNIQUES}

Samples were drawn from the entire population, which served as a representative of the population from which result was obtained. Purposive sampling technique was used to obtain a sample of 8 schools. The sample size was in line with Krejcie and Morgan's (1970) table for determining sample size. The distribution determined the number of students' sample size from each school. Three (3) schools were selected from co-educational, boys and girls, another three (3) from boys only, and two (2) schools from girls only.

Proportionate sampling method was used to pick the sample size from each school. Thus, the total number of the population in the (8) schools selected was two thousand seven hundred and sixty one $(2,761)$ students and the total number of the sample size from the (8) schools of (384) students gave the sample size of the students (boys \& girls) from each school.

The researcher selected eight (8) schools out of the thirty-two (32) schools in Katsina metropolis. The direct and purposive selection of these eight schools is what (Fox, 1969) called deliberate selection, if within a population there were some elements which a researcher believes are crucial to study, then the only way to ensure this is to deliberately select them. Consequently, the eight (8) schools formed the sample for the study. A total of one hundred and ninety-two boys (192) and a total of one hundred and ninety-two (192) girls were selected. Thus a total number of three hundred and eighty four (384) students in Junior Secondary Schools in Katsina metropolis were selected.

Table 1: Sample for the Study

\begin{tabular}{|c|c|c|c|c|c|c|}
\hline \multirow{3}{*}{ SN } & \multirow{3}{*}{ Schools } & \multicolumn{4}{|c|}{ School Type } & \multirow{3}{*}{ Total } \\
\hline & & \multicolumn{2}{|c|}{ Mixed } & \multirow{2}{*}{ Boys } & \multirow{2}{*}{ Girls } & \\
\hline & & Boys & Girls & & & \\
\hline 1 & Katsina College Katsina & 28 & 28 & - & - & $56(14.6 \%)$ \\
\hline 2 & Government College Katsina & 33 & 32 & - & - & $65(16.9 \%)$ \\
\hline 3 & SUNCAIS Katsina & - & - & 125 & - & $125(32.6 \%)$ \\
\hline 4 & Gobarau Academy Katsina & - & - & - & 14 & $14(3.6 \%)$ \\
\hline 5 & Damale College Katsina & - & - & 6 & 18 & $24(6 \%)$ \\
\hline 6 & Hikima College Katsina & - & - & - & 12 & $12(3.6 \%)$ \\
\hline 7 & Aunty Ramatu Sec. School Katsina & - & - & - & 18 & $18(4.7 \%)$ \\
\hline 8 & Government Girls College Katsina & - & - & - & 70 & $70(18.2 \%)$ \\
\hline \multicolumn{2}{|c|}{ TOTAL } & 61 & 60 & 131 & 132 & $384(100 \%)$ \\
\hline
\end{tabular}

\section{INSTRUMENTATION}

To achieve the objectives of this study, two (2) sets of instruments were used in measuring students' motivation and their academic performance. Both instruments were adopted by the researcher.

\section{DESCRIPTION OF EMOTIONAL INTELLIGENCE QUESTIONNAIRE (EIQ)}

This instrument used in measuring emotional intelligence of the students in Katsina metropolis was adopted from Kolo (2006). It has 30 items on emotional intelligence characteristics. Fifteen (15) items are positively worded while the other fifteen (15) items are negatively worded. Therefore, strongly agree (SA) indicates high score which determine high level of emotional intelligence while on the other hand strongly disagree (SDA) indicates low score which determine low level of emotional intelligence.

Validity of Eiq 


\section{Emotional Intelligence as Correlate of Academic Performance among Junior Secondary School Students in Katsina Metropolis}

To ensure the validity of the instruments for this study, its original owner had subjected it to various processes to ensure face, content and construct validity. Since the instrument has been found to be valid by Kolo (2006), the current researcher decided to adopt it for use in this study

\section{Reliability of Eiq}

The questionnaire was administered to 120 respondents in Kwara state by its original owner. Using the Cronbach's Alpha, a test retest reliability coefficient value of 0.78 was obtained. This shows that the instrument was found to be reliable by Kolo (2006) which made the current researcher to adopt it for use in this study.

\section{Administration of Eiq}

The administration of emotional intelligence questionnaire (EIQ) was in line with 4 points Likert scale style. The responses were strongly agree, agree, disagree and strongly disagree. (i.e. $S A=4, A=3, D=2, S D=1$ ). For positively worded items the scoring pattern is 4 to 1 in descending order. While for negatively worded items, the scoring will be reversed i.e. from 1 to 4 in ascending order.

\section{RESEARCHER-DESIGNED TESTS IN ENGLISH LANGUAGE AND MATHEMATICS (ELMT)}

The Junior Secondary School students were given a test in English language and Mathematics which contained forty items extracted from the syllabus of JSS II used by the researcher. The result obtained from the ELMT was converted in grades A, B, C, D or E to numerical expression to allow for statistical operation. Grade A with scores above 85 was represented by 4.0 points while grade B with 65-84 marks was represented as 3.0 points. Grade C with 55-64 marks was represented as 2.0 points and grade D with 40-54 marks was represented by 1.0 points. Grade $\mathrm{E}$ with less than 40 marks is represented as 0 point. 4.0 points was the highest score a student can obtain. The Grade points Average (GPA) for JSS students is calculated by adding the grades obtained from the two disciplines under consideration, English and Mathematics and divided by 2.

\section{Validity of ELMT}

The 40 items on English and Mathematics were checked and validated by some teachers in secondary schools under Katsina State Ministry of Education. Furthermore, experts/supervisors in the Departments of English and Mathematics in Usmanu Danfodiyo University Sokoto examined the content validity of the items and they adjudged the instrument as valid for the conduct of the study.

\section{Reliability of ELMT}

Using the measures of stability, a set of 40 students from Government Girls College Katsina sat for the test concurrently, after four weeks the same group of JSS II students sat again for a re-test of the same test items in order to ascertain the reliability of the items or otherwise. At the end, the reliability of the tests on the subjects English and Mathematics produced co-efficient Alphas of 0.73 and 0.65 as reliability indices.

\section{PROCEDURE FOR DATA COLLECTION}

The data was collected by the researcher and his assistants using face to face and direct delivery techniques in administration and collection of the questionnaires so as to ensure significant return rate of completed questionnaires

Furthermore, the scores obtained from these instruments were subjected to Pearson product moment correlation coefficient ' $r$ ' statistics which was used for testing the formulated hypotheses. The justification for Pearson product moment correlation coefficient for hypotheses 1 to 3 was because these hypotheses were looking for relationship between two variables.

\section{Presentation, Analyses and Interpretation of Result}

H01: There is no significant relationship between emotional intelligence and academic performance of Junior Secondary School students.

This hypothesis was tested by subjecting the emotional scores of students and their academic performance to Pearson's correlation analysis as shown in table 2 .

Table 2: Relationship between Students' Emotional intelligence and their Academic Performance.

\begin{tabular}{lllllll}
\hline Variables & $\mathrm{N}$ & Mean & $\begin{array}{l}\text { Std. } \\
\text { Deviation }\end{array}$ & r-Cal & p-Value & Decision \\
\hline Emotional Intelligence & 384 & 86.94 & 20.940 & -.215 & .000 & $\mathrm{H}_{0}$ Rejected \\
Academic Performance & 384 & 88.22 & 21.189 & & & \\
\hline
\end{tabular}

Source: Researcher's Fieldwork, 2021

From the result of table 2, students' emotional intelligence and academic performance was positively related and significant, Pearson's $r(382)=-.215, p<.05$. This indicates a significant relationship between students' emotional intelligence and their academic performance because the $\mathrm{p}$-value is less than the .05 level of significance. Therefore, $\mathrm{H}_{1}$ which states that there is no 


\section{Emotional Intelligence as Correlate of Academic Performance among Junior Secondary School Students in Katsina Metropolis}

significant relationship between students' emotional intelligence and academic performance of junior secondary school students was rejected.

H02: There is no significant relationship between male students' emotional intelligence and their academic performance.

This hypothesis was tested by subjecting male students' emotional intelligence scores and their academic performance to Pearson's correlation analysis as shown in table 3 .

Table 3: Relationship between Male Students' Emotional intelligence and their Academic Performance.

\begin{tabular}{lllllll}
\hline Variables & $\mathrm{N}$ & Mean & $\begin{array}{l}\text { Std. } \\
\text { Deviation }\end{array}$ & r-Cal & p-Value & Decision \\
\hline Emotional Intelligence & 192 & 88.41 & 20.298 & -.190 & .008 & $\mathrm{H}_{0}$ Rejected \\
Academic Performance & 192 & 87.16 & 20.464 & & & \\
\hline
\end{tabular}

Source: Researcher's Fieldwork, 2021

From the result of table 3, male students' emotional intelligence and their academic performance was positively related and significant, Pearson's $r(192)=-.190, p<.05$. This indicates a significant relationship between male students' emotional intelligence and their academic performance because the p-value is less than the .05 level of significance. Therefore, $\mathrm{HO}_{2}$ which states that there is no significant relationship between male students' emotional intelligence and their academic performance was rejected.

H03: There is no significant relationship between female students' emotional intelligence and their academic performance. This hypothesis was tested by subjecting the female students' emotional intelligence and academic performance scores of students to Pearson's correlation analysis as shown in table 4.

Table 4: Relationship between Female Students' emotional intelligence and their academic Performance

\begin{tabular}{lllllll}
\hline Variables & $\mathrm{N}$ & Mean & $\begin{array}{l}\text { Std. } \\
\text { Deviation }\end{array}$ & r-Cal & p-Value & Decision \\
\hline Emotional Intelligence & 192 & 85.48 & 21.516 & -.233 & .001 & $\mathrm{H}_{0}$ Rejected \\
Academic Performance & 192 & 89.28 & 21.893 & & & \\
\hline
\end{tabular}

Source: Researcher's Fieldwork, 2021

From the result of table 4, female students' emotional intelligence and their academic performance was positively related and significant, Pearson's $r(382)=-.233, p=.001$. This indicates a significant relationship between female students' emotional intelligence and their academic performance because the p-value is less than the .05 level of significance. Therefore, $\mathrm{H}_{3}$ which states that there is no significant relationship between female students' emotional intelligence and their academic performance was rejected.

\section{DISCUSSION}

The first finding indicates that emotional intelligence of students has a significant relationship on academic performance among junior secondary school students. This then support the assertion by Cole (2000) that emotional motivation is a term used to describe those processes, both initiative and rational by which people seek to satisfy the basic drives, perceived needs and personal goals, which trigger off human behavior. Likewise, it lent credence to how Robin (1989) describes teachers' motivation as the willingness to exert high levels of efforts towards organizational goals conditioned by the efforts ability to satisfy some individual needs. In other words emotional intelligence is a management function that stimulates individuals to accomplish laid down institutional goals. It is purposive, designated and goal-oriented behaviour that involves certain forces acting on or within the individual in order to initiate, sustain and direct behaviour (Olochukwu, 2000).

The other findings indicate that female and male students' emotional intelligence has significant relationship to their academic performance. This supported Kolo's (2006) assertion that a child's emotional state at school is said to influence his/her selective attention, recall, event interpretation, decision making, motivation and problem solving abilities. It also support findings by Asma'u (2013) which revealed that emotional intelligence and academic performance are strongly and positively related. The findings somehow also affirmed the assertion that women tend to be more emotions better and that they have a greater agility as regards certain interpersonal skills (Sanchez and Fernandez-Berrocal, 2006). Students' academic performance, for instance, recognizes other people's emotions better, are more perspective and have greater empathy (Aquino 2003, Argyle, 1990, Hargie, Saunders and Dickson 1995). In addition, some evidence exists that certain areas of the brain dedicated to processing emotions could be larger in women than in men (Baron-Cohen, 2003, 2005; Gur, and Gunning-Dixon, Bilker \& Gur, 2002). It is also believed that there is a difference in cerebral cavity based on sex (Jausovec \& Jausovec, 2005).

\section{CONCLUSION}




\section{Emotional Intelligence as Correlate of Academic Performance among Junior Secondary School Students in Katsina Metropolis}

From the findings and discussion of results, it was concluded that students emotional intelligence has a significant effect on their academic performance among junior secondary school students in Katsina metropolis. Conclusively then it is important for teachers and other stakeholders in education to emphasize on emotional training. That is, training on the development of motivational skills among junior secondary schools in Katsina metropolis.

\section{Implications for counseling}

The following are the implications for counselling:

i. School counselors should employ the extensive use of individual and group counselling techniques to help students improve on their school adjustment and academic performance. School counselling programmes should apply the tenets of existing counselling theories such as Fredrick Thorne (1945-1980) eclectic counseling theory.

ii. School counselors could serve as a link between students and teachers of various school subjects with the view to helping the teachers to take cognizance of the gender differences among learners and give them differential and specific treatment in line with their gender and motivation that is, counselors should provide services that would help teachers gain acquaintance with their students as unique, distinct and dynamic individuals.

iii. Counsellors should play significant roles in counselling students on the need to engage in activities which are self-fulfilling and which also guarantee the positive overall development of the individual and the society in general.

\section{RECOMMENDATIONS}

Based on the findings of the study carried out on relationship between students' emotional intelligence and academic performance of junior secondary school (JSSII) students in Katsina metropolis, the following recommendations were made:

i. Emotional intelligence of students has significant effect therefore, guidance and counselors should encourage and support students to develop and improve their emotional intelligence and academic performance.

ii. Male students' emotional intelligence and academic performance was positively related and significant thus, there should be improvement of effective teaching strategies for students of junior secondary schools.

iii. Female students' emotional intelligence has relation to their academic performance therefore teachers, guidance and counselors should increase their work diligently so that all students are catered for.

\section{REFERENCES}

1) Adeyinka, A. (2002). Teacher Quality and Quantity as correlates of Secondary School Students'academic Performance. The Nigerian Journal of Guidance and Counseling, 8(1), $98-111$

2) Akinboye, J. O. (2002). Creativity and innovation in life and the Psychological principles for success in life and work place. Ibadan - Nigeria: Sterling Horden Publishers.

3) Akinboye, J. O. (2003): Creativity, innovation and success. Ibadan-Nigeria: Sterling Horden Publishers.

4) Aquino, A. E. (2003). Gender differences and age in a Group of web Browser's Emotional Intelligence. Unpublished thesis.

5) Asma'u, M. A. (2013). The relationship among emotional Intelligence, Self-Concept and academic Performance, Implication for Counselling. MEd Dissertation Submitted to the Department of Education and Extension Services, Usmanu Danfodiyo University Sokoto.

6) Bahman, S. \& Maffini H. (2008). Developing children's Emotional intelligence. London: Cromwell Press Ltd.

7) Baron-Cohen, S. (2003). The essential difference: Men, Women and the extreme Male brain. London: Allen Lane.

8) Baron-Cohen, S. (2005). The essential difference: Male and Female brain. Phi Kappa Phi Forum, 85, 22-26.

9) Cole, G.A. (1986). Management Theory and Practice. Aldineplace, London: Lens Educational.

10) Fafunwa, A. B. (1976). History of Education in Nigeria. London: Allen and Unwin.

11) Federal Government of Nigeria (1998). Reviewed National Policy on Education. Lagos: Ministry of Education. Author.

12) Forman, E.M. \& Davies, P.T. (2003). Family Instability and Young Adolescent Effects onParenting Quality and Adolescent Appraisal of family Security, Adolescent Psychology, 32, $94-105$

13) Gur, R. C., Gunning-Dixon, F., Bilker, W. B., and Gur, R. E. (2002). Sex differences in temporo-limbic and frontal brain volumes of healthy adults. Cerebral Cortex, 12, 998- 1003.

14) Hargie, O., Saunders, C., \& Dickson, O, (1995). Social Skills in Interpersonal Communication. London: Routledge.

15) Jausovec, N. \& Jausovec, K. (2005). Sex differences in brain activity related to general and emotional intelligence. Brain and Cognition, 59, 277-286.

16) Kolo, E. N. (2006). Relationship between Emotional Intelligence and Academic Performance of Secondary School Students in Niger State, Nigeria. Unpublished Master Project, University of Ilorin. 


\section{Emotional Intelligence as Correlate of Academic Performance among Junior Secondary School Students in Katsina}

Metropolis

17) Krejcie R. \& Morgan, D. W. (1970). Determining sample size for Research Activities. Educational and Psychological Measurement, 30.

18) Lane, P. L. (1998). The impact of teaching styles on students' style and academic performance outcome. PhD Theses, University of Northern Colorado.

19) Mcluskey, A. (1997). Emotional Intelligence in schools. Retrieved 24 $4^{\text {th }}$ October 2006 from http://ei.haygroup.com.

20) Mont, G. (2008). Human abilities: Emotional intelligence. Annual Review of Psychology, 59, 507-536.

21) Purkey, W.W. (1970). Fundamentals of Experimental Psychology: A Comparative Approach. Englewood Cliffs: PrenticeHall Inc.

22) Robbins, S. P. (1989). Organizational Behaviour. Prentice-Hall International Inc.

23) Rogers, C. (1951). Client-centered Therapy: Its current Practice Implications and Theory. Boston: Houghton-Mifflin.

24) Salawu A. A. (1993). Relationship between Adolescent Perceptions of Parents' Behavior and their Self-Concept. Ife PsychologiA: An International Journal, 3(2), 148-162.

25) Salawu, A. A. (2000). The impact of Home Background on Academic Achievement and Its Implication for Counseling. Sokoto Educational Review 4, 55-59.

26) Salawu, A. A. (2010). Ethno-religious Conflicts in Nigeria: Causal Analysis and proposals for new management strategies. The Nigerian Journal of Guidance and Counseling, 8(1).

27) Salovey, P. \& Mayer, J. D. (1990). Emotional Intelligence. Imagination, Cognition and Personality, 9, 185-211

28) Sanchez, M. T., \& Fernandez-Berrocal, P. (2006). Analysis of the relationship between perceived Emotional Intelligence and Mental Health in Couples. Ansiedad y Estres, Electronic Journal of Educational Psychology.12, 343-353. 